\title{
THE MEDIATING ROLES OF GDP ON THE RELATIONSHIP BETWEEN INCOME INEQUALITY AND LIFE EXPECTANCY
}

\author{
Chia-Chang Chuang \\ Department of International Business, National Taipei University of Business, \\ No.321, Sec. 1, Jinan Rd., Zhongzheng District, Taipei City 100, Taiwan (R.O.C.) \\ Email: jjjuang@ntub.edu.tw
}

Published online: 1 December 2021

To cite this article: Chuang, C. C. (2021). The mediating roles of GDP on the relationship between income inequality and life expectancy. Asian Academy of Management Journal, 26(2), 101-116. https://doi.org/10.21315/aamj2021.26.2.5

To link to this article: https://doi.org/10.21315/aamj2021.26.2.5

\begin{abstract}
This study examined the mediation effect of gross domestic product (GDP) on the relationship between life expectancy and income inequality based on data from 23 Organisation for Economic Co-operation and Development (OECD) countries for 2004 through 2014. To form a theoretical framework, Preston curve and Kuznets curve were employed. The study set up a mediation model with life expectancy as an outcome variable, $G D P$ as a mediator variable, and three variables characterising income inequality as predictor variables: Gini index, income share held by highest $20 \%$, and poverty headcount ratio at US\$1.90 a day. The study found that GDP clearly mediates the effects of the predictor variables on life expectancy, although the magnitudes of the effects vary. This study takes an important initial step in exploring the mediation effect of GDP on the relationship between life expectancy and income inequality.
\end{abstract}

Keywords: life expectancy, income inequality, GDP, mediation, Kuznets curve, Preston curve

(C) Asian Academy of Management and Penerbit Universiti Sains Malaysia, 2021. This work is licensed under the terms of the Creative Commons Attribution (CC BY) (http://creativecommons. org/licenses/by/4.0/). 


\section{INTRODUCTION}

Economic growth is recognised to have a positive influence on mortality rates (Acemoglu \& Johnson, 2007; Banister \& Zhang, 2005; Preston, 1975, 2007; Schnabel \& Eilers, 2009). Preston $(1975,2007)$ found a positive relationship between national income per head and life expectancy, as illustrated by Preston curve. Similarly, economic growth has been related to general changes in society (Hagen, 1963; Kuznets, 1955). Kuznets (1955) found the relationship between economic growth and unbalanced income distribution. According to Kuznets (1955), income distribution would be unbalanced in earlier stage of industrialisation, but the gap in income inequality would be narrowing as industrialisation and urbanisation proceed.

Starting from the concept of Preston curve, this study will set up the mediation framework for the relationship between income inequality and life expectancy. The Preston curve shows that economic growth has a significant effect on life expectancy (Banister \& Zhang, 2005; Preston, 1975, 2007; Schnabel \& Eilers, 2009). And given the Kuznets curve, economic growth is one reason why income inequality changes showing inverted U-shaped pattern (Acemoglu \& Robinson, 2002; Agénor, 2016; Cingano, 2014; Egawa, 2013; Kuznets, 1955). From this, it might be deduced that income inequality has a relationship with life expectancy via a mediator of gross domestic product (GDP). This empirical paper shows that GDP mediates the relationship between income inequality and life expectancy from the conceptual framework of Kuznets curve and Preston curve as shown in Figure 1.

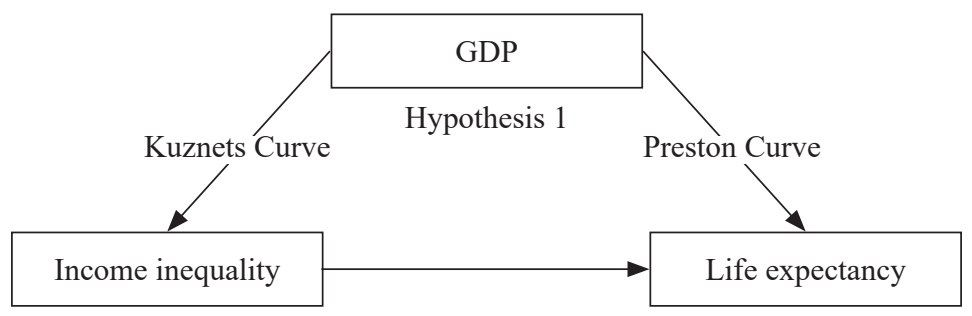

Figure 1. Conceptual framework

An issue of life expectancy has engaged current scholarship across a range of fields. Life expectancy will be examined in connection with income inequality, and the study will be directed at the connection via GDP. The underlying goal of this study lies in the provision of a valuable reference for understanding the issue of life expectancy. 


\section{LITERATURE REVIEW}

For a better understanding of this study, it is necessary to examine two curve theories: Preston curve and Kuznets curve. Thus, this section will start out by examining those theories and then look at how topic of income inequality was addressed in relation to life expectancy in the literature.

\section{Theoretical Background}

\section{Preston curve}

Preston $(1975,2007)$ found that economic growth is positively related to life expectancy. The betterment in income level promotes better access to housing, education, health services, and other factors which have a tendency for improving health condition (Bloom \& Canning, 2007; Dalgaard \& Strulik, 2014; Preston, $1975,2007)$. For this reason, better living conditions is defined as motivation of income growth, and such motivation coupled with socioeconomic aspects exerts an influence on an increase in life expectancy (Preston, 1975, 2007). According to Preston $(1975,2007)$, each of the factors such as literacy, nutrition, technological advance, vaccination, medical and public health service, each of whose levels depends on economic level, is credited with improvement in life expectancy.

Preston curve shows a relationship between economic growth and life expectancy with national income per head plotted on the x-axis and life expectancy at birth plotted on the y-axis (Preston, 1975, 2007). Preston curve shows a dramatic rise to start with but the higher the income level, the more the curvature of the curve flattens out (Preston, 1975, 2007). It illustrates that life expectancy is highly sensitive to a change in income level in countries which show low levels of income (Lutz \& Kebede, 2018; Preston, 1975, 2007). At the same time, it also denotes that life expectancy is less sensitive to a change in income level in countries which show high levels of income (Lutz \& Kebede, 2018; Preston, 1975, 2007).

\section{Kuznets curve}

Kuznets (1955) examined the relationship between economic growth and inequality of income distribution. As nations shift from an agrarian-based economy to an industrial-based economy, rural labour moves to urban area to higher-income opportunities, and it elevates the degree of inequality between urban and rural areas (Barro, 2000; Kuznets, 1955). And further, in the early phase of industrialisation, a massive influx of rural labour into urban area had led to low levels of wages in urban area, and it had been widening inequality between the higher-income group 
such as employer and lower-income group such as labourer from rural area (Barro, 2000; Kuznets, 1955). As a result, the relationship between economic growth and the degree of inequality shows a positive tendency (Barro, 2000; Kuznets, 1955). But according to Kuznets (1955), when the nation enters the latter phase of industrialisation and the income reaches a certain level, the degree of inequality starts to decrease. The process of industrialisation entails democratisation, welfare and technological innovation, which may help offset the gap of inequality (Barro, 2000; Chong, 2004; Kuznets, 1955). Thus in the latter phase of industrialisation, the relationship between economic growth and the degree of inequality shows a negative tendency (Barro, 2000; Kuznets, 1955).

Kuznets curve shows the effect of economic growth on inequality (Barro, 2000; Deininger \& Squire, 1996; Kuznets, 1955). The whole relationship between income per capita and inequality shows an inverted U-shaped (Barro, 2000; List $\&$ Gallet, 1999). The inverted U-shaped illustrates the basic concept of the theory which Kuznets suggested (Barro, 2000).

\section{The connection between life expectancy and income inequality}

Enough has been said to demonstrate that there is a considerable relationship between income and health (Kawachi \& Kennedy, 1999). But recent scholarship has been inclined to consider the relationship between income inequality and health (De Vogli et al., 2005; Pickett \& Wilkinson, 2015; Wilkinson \& Pickett, 2009). Because a few developed countries have displayed relatively poor levels of health indicators compared with other developed countries, though they have achieved high growth for decades (Kawachi \& Kennedy, 1999; Pickett \& Wilkinson, 2015; Wilkinson, 1992). In recognition of this phenomenon, Wilkinson (1992) supposed that health status of population might be dictated by the degree of income inequality. In fact, many developed countries have shown a large increase in income inequality for decades (Subramanian \& Kawachi, 2004). An unbalanced income distribution leads to unequal distribution of resources (Lynch et al., 2001; Lynch et al., 2000; Wilkinson, 1992). Wilkinson (1992) noted that the disparity in economic status gives rise to a wide range of difference in morbidity and mortality. Health condition of individual is dependent on income level of the individual (Subramanian \& Kawachi, 2004). If income redistribution from the wealthy to the poor is realised, the poor might be expected to be healthier (Wilkinson \& Pickett, 2009). Because redistribution would improve the purchasing power of the poor and enable them to have more money to access to healthcare (Wilkinson \& Pickett, 2009). Indicators of health in developed countries may be dictated more by reducing income inequality than economic growth (Wilkinson \& Pickett, 2009). 
Income distribution is one of social indices showing a degree of investment in public sector (Kennedy et al., 1996). Society that suffers from a huge and unjust discrepancy in wealth distribution has a propensity for underinvestment in public goods such as healthcare (Kennedy et al., 1996). The health condition of individuals also has a strong association with policies dealing with the widening gap in income distribution (Kawachi \& Kennedy, 1999; Kennedy et al., 1996). According to Kawachi and Kennedy (1999), the income inequality that already exists can be mitigated by the policy lever, because policies such as the minimum wage and the earned income tax credit can narrow the gap between the wealthy and the poor. And those policies ease the tax burdens of the poor and enable them to have more money to afford a healthcare service (Kawachi \& Kennedy, 1999). High income inequality may increase absolute poverty which may adversely affect healthcare and nutrition (Pickett \& Wilkinson, 2015; Wilkinson, 2002). And growing inequality in favour of a small minority of the population may incite social and political tension and impede sustainable development of a country (Coburn, 2000). It may be a serious impediment to realisation of social welfare such as healthcare (Coburn, 2000).

\section{METHODOLOGY}

\section{Data Description}

This study will draw on statistical data from 23 Organisation for Economic Co-operation and Development (OECD) countries, which is collected from the World Bank databank. Twenty-three OECD countries selected are Republic of Austria, Kingdom of Belgium, Czech Republic, Kingdom of Denmark, Republic of Estonia, Republic of Finland, French Republic, Hellenic Republic, Hungary, Republic of Iceland, Ireland, Republic of Latvia, Republic of Lithuania, Grand Duchy of Luxembourg, Kingdom of the Netherlands, Kingdom of Norway, Portuguese Republic, Slovak Republic, Republic of Slovenia, Kingdom of Spain, Kingdom of Sweden, Republic of Turkey, and United Kingdom of Great Britain and Northern Ireland. A period for data analysis is set to as 2004 through 2014 because data for the period are mostly available, and data for the period since 2015 are including missing observations. For analysis, this study will employ the specific variables: life expectancy at birth, total (years), GDP per capita, purchasing power parity (PPP) (current international dollar), Gini index (World Bank estimate), income share held by highest $20 \%$, and poverty headcount ratio at $\$ 1.90$ a day (2011 PPP) (percentage of population). The following descriptions of each specific variable rely on definitions of World Bank databank. 


\section{Specific Variables}

\section{Life expectancy at birth, total (years)}

Life expectancy at birth refers to the number of years a newborn infant would live if prevailing patterns of mortality at the time of its birth were to stay the same throughout its life. Life expectancy at birth employed here is the average number of years a newborn is expected to live if mortality patterns at the time of its birth remain constant in the future. It is calculated in a period life table which provides a snapshot of population's mortality pattern at a given time. It therefore does not reflect the mortality pattern that a person actually experiences during their own life, which can be calculated in a cohort life table. In the process of analysis, the term le will stand for life expectancy at birth, total (years).

\section{GDP per capita, PPP (current international dollar)}

GDP per capita, PPP indicates GDP per capita based on PPP. GDP per capita, PPP is GDP per person converted to international dollars using PPP rates. GDP at purchaser's prices is the sum of gross value added by all resident producers in the economy plus any product taxes and minus any subsidies not included in the value of the products. It is calculated without making deductions for depreciation of fabricated assets or for depletion and degradation of natural resources. In the process of analysis, the term GDP will stand for GDP per capita, PPP (current international dollar).

\section{Gini index (World Bank estimate)}

Gini index measures the extent to which the distribution of income among individuals or households within an economy deviates from a perfectly equal distribution. The concept was first introduced in 1912 by Corrado Gini (Ceriani \& Verme, 2011). Lorenz curve plots the cumulative percentages of total income received against the cumulative number of recipients, starting with the poorest individual or household (Atkinson, 1970). Gini index measures the area between Lorenz curve and a hypothetical line of absolute equality (Subramanian \& Kawachi, 2004). The Gini index is computed by a ratio of areas on Lorenz curve. If the area between the line of perfect equality and Lorenz curve is $\mathrm{A}$, and the area below the Lorenz curve is $\mathrm{B}$, then the Gini index is $\mathrm{A} /(\mathrm{A}+\mathrm{B})$. Thus, the Gini index of 0 denotes perfect equality, whereas the Gini index of 1 denotes perfect inequality. In the process of analysis, the term GINI will stand for Gini index (World Bank estimate). 


\section{Income share held by highest $20 \%$}

In general, measures of income inequality represent unbalanced distribution of money in the population (Lynch et al., 1998). One of measure commonly used in gauging income inequality is income share ratios at percentiles of distribution (Lynch et al., 1998). Income share held by highest 20\% is the share that accrues to subgroups of population indicated by the second decile. The percentage share by decile may not sum to 100 due to rounding. In the process of analysis, the term income_h20 will stand for income share held by highest $20 \%$.

\section{Poverty headcount ratio at $\$ 1.90$ a day (2011 PPP) (percentage of population)}

International comparisons of poverty estimates entail both conceptual and practical problems. Countries have different definitions of poverty, and consistent comparisons across countries can be difficult. The welfare of people living in different countries can be measured on a common scale by adjusting for differences in the purchasing power of currencies. As differences in the cost of living across the world evolve, the international poverty line has to be periodically updated using new PPP price data to reflect these changes. Poverty measures based on international poverty lines attempt to hold the real value of the poverty line constant across countries, as is done when making comparisons over time. The current extreme poverty line is set at $\$ 1.90$ a day in 2011 PPP terms, which represents the mean of the poverty lines found in 15 of the poorest countries ranked by per capita consumption. Poverty headcount ratio at $\$ 1.90$ a day is the percentage of the population living on less than $\$ 1.90$ a day at 2011 international prices. In the process of analysis, the term poverty 1.90 will stand for poverty headcount ratio at $\$ 1.90$ a day (2011 PPP) (percentage of population).

\section{Mediation Model}

In mediation model, mediator has an effect of intervention on the relationship between predictor and outcome (Baron \& Kenny, 1986). There are a series of regression equations to estimate mediation model (Baron \& Kenny, 1986; Fitrianto \& Midi, 2013; Rijnhart et al., 2017).

$$
\begin{aligned}
& Y=i_{1}+c X+e_{1} \\
& M=i_{2}+a X+e_{2} \\
& \mathrm{Y}=i_{3}+c^{\prime} X+b M+e_{3}
\end{aligned}
$$


$Y$ is the outcome variable, $X$ is the predictor variable, and $M$ is the mediator (Fitrianto \& Midi, 2013). The coefficient $c$ denotes the overall effect of the predictor variable $X$ on the outcome variable $Y$ in Equation 1. The coefficient $a$ denotes the effect of the predictor variable $X$ on the mediator variable $M$ in Equation 2 . The coefficient $c^{\prime}$ denotes the direct effect of the predictor variable $X$ on the outcome variable $Y$, and the coefficient $b$ denotes the effect of the mediator variable $M$ on the outcome variable $Y$ in Equation 3. According to Baron and Kenny (1986), the following conditions should be met in order to build a mediation model: first, the predictor variable $X$ with the coefficient $c$ should show statistical significance in Equation 1; second, the predictor variable $X$ with the coefficient $a$ should show statistical significance in Equation 2; third, in Equation 3, if the predictor variable $X$ with the coefficient $c^{\prime}$ does not show statistical significance and the mediator variable $M$ with the coefficient $b$ shows statistical significance and the value of the coefficient $c^{\prime}$ is close to 0 , then the findings support full mediation model; fourth, in Equation 3, if both the predictor variable $X$ with the coefficient $c^{\prime}$ and the mediator variable $M$ with the coefficient $b$ show statistical significance and the absolute value of the coefficient $c^{\prime}$ is less than the absolute value of the coefficient $c$, then the findings support partial mediation model. According to Rijnhart et al. (2017), the indirect effect can be computed by the product of the coefficients $a$ and $b$ or the difference between the coefficients $c$ and $c^{\prime}$. And the proportion mediated can be computed by either $a b /\left(a b+c^{\prime}\right)$, $a b / c$, or $1-\left(c^{\prime} / c\right)$ (Baron \& Kenny, 1986; Fitrianto \& Midi, 2013; Freedman et al., 1992; MacKinnon et al., 2007a; MacKinnon et al., 1995; Rijnhart et al., 2017).

\section{Mediation model for the relationship between life expectancy and income inequality with a mediator variable of GDP}

Three specific variables representing income inequality are Gini index (World Bank estimate), income share held by highest $20 \%$, and poverty headcount ratio at $\$ 1.90$ a day (2011 PPP) (percentage of population). The mediation model is built with GDP as a mediator variable, life expectancy as an outcome variable, and three specific variables as predictor variables, as illustrated in Figure 2. 


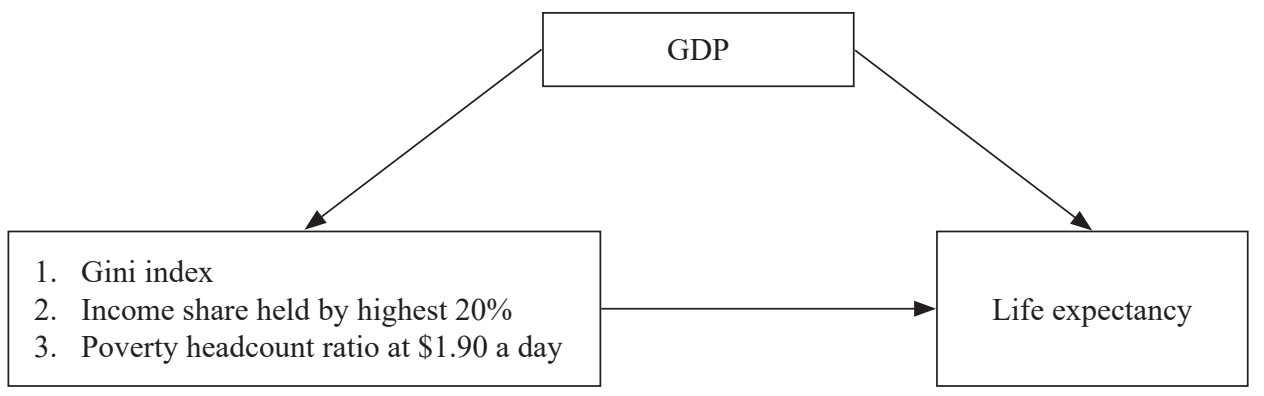

Figure 2. Mediation model of the relationship between life expectancy and the specific variables representing income inequality

With regression approach of Baron and Kenny (1986), the mediating role of GDP on the relationship between life expectancy and three specific variables is examined as follows:

$$
\begin{aligned}
& \text { le } e_{i t}=\beta_{1,0}+\beta_{1,1} \text { GINI }_{i t}+\beta_{1,2} \text { income_h20 } 0_{i t}+\beta_{1,3} \text { poverty1.90 } 0_{i t}+\varepsilon_{1, i t} \\
& \mathrm{GDP}_{i t}=\beta_{2,0}+\beta_{2,1} \mathrm{GINI}_{i t}+\beta_{2,2} \text { income_h20 } 0_{i t}+\beta_{2,3} \text { poverty1.90 } 0_{i t}+\varepsilon_{2, i t} \\
& \mathrm{le}_{i t}=\beta_{3,0}+\beta_{3,1} \text { GINI }_{i t}+\beta_{3,2} \text { income_h20 } 0_{i t}+\beta_{3,3} \text { poverty } 1.90_{i t} \\
& +\beta_{3,4} \mathrm{GDP}_{i t}+\varepsilon_{3, i t}
\end{aligned}
$$

\section{EMPIRICAL RESULTS}

\section{Mediation Analysis}

To examine the relationship between life expectancy and income inequality, being mediated by GDP, the aforementioned regression equations are employed. First, the estimated regression equation for the overall effects of three predictor variables on life expectancy is set up as follows:

$$
\begin{aligned}
l e_{i t}= & 110.2786+2.0490 G I N I_{i t}+(-2.4173) \text { income_h20 } 20_{i t} \\
& +(-0.9248) \text { poverty } 1.90_{i t}+\varepsilon_{1, i t}
\end{aligned}
$$

The overall effects indicate the relationship between each predictor variable and life expectancy without consideration of a mediator variable of GDP. 


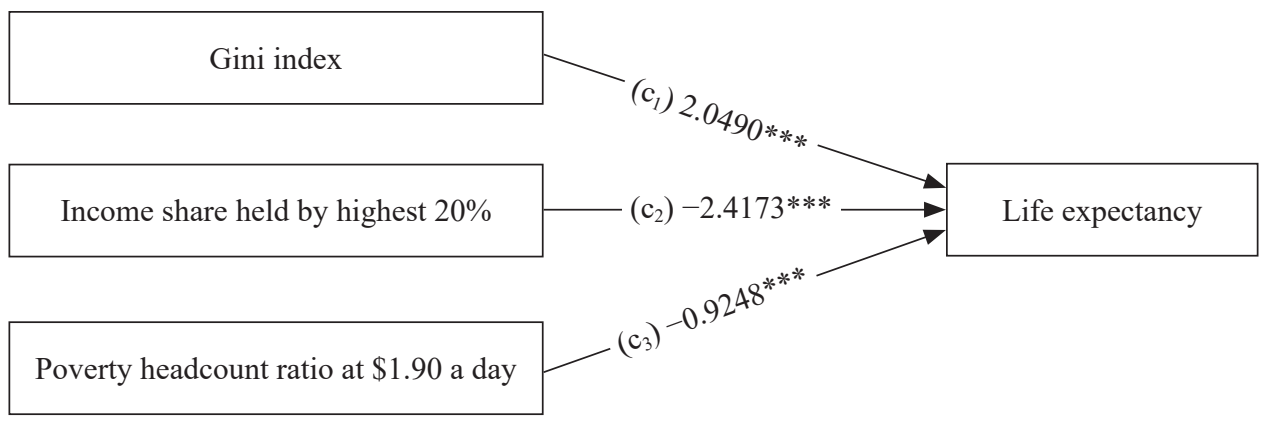

Figure 3. The overall effects of three variables specified for income inequality on life expectancy

Note: * indicates significance at the $10 \%$ level, ** at the $5 \%$ level, and *** at the $1 \%$ level, respectively

As illustrated in Figure 3, le is predicted by each of GINI, income_h20, and poverty 1.90, the overall effects are quantified by the respective coefficients: $2.0490(t=8.9295, p<0.0000),-2.4173(t=-8.9890, p<0.0000)$, and $-0.9248(t=-4.2727, p<0.0000)$ in the order of GINI, income_h20, and poverty 1.90. The next step is to decompose the overall effect into its direct and indirect elements.

$$
\begin{aligned}
\mathrm{GDP}_{i t}= & 145994.9384+7038.4746 G_{I N I}+(-8328.3955) \text { income_h20 } \\
& +(-5775.0942) \text { povertyl.90 } \\
& +\varepsilon_{i t}+\varepsilon_{2, i t}
\end{aligned}
$$

In Equation 8 where GDP is an outcome variable, each of $7038.4746(t=6.6777$, $p<0.0000),-8328.3955(t=-6.7422, p<0.0000)$, and $-5775.0942(t=-5.8086$, $p<0.0000)$ indicates the effect of the corresponding predictor variable on GDP.

$$
\begin{aligned}
l e_{i t}= & 87.6513+0.9582 \operatorname{GINI}_{i t}+(-1.1265) \text { income }_{2} h 20_{i t} \\
& +(-0.0297) \text { poverty } 1.90_{i t}+0.0002 \mathrm{GDP}_{i t}+\varepsilon_{3, i t}
\end{aligned}
$$

In Equation 9, an estimate of each predictor variable corresponds to the effect of the predictor variable on life expectancy while the other two predictor variables and a mediator variable are held constant. In equation (9), le is predicted by three predictor variables of GINI, income_h20, and poverty 1.90 plus a mediator variable of GDP. Coefficients of GINI, income_h20, and poverty1.90 are $0.9582(t=5.4239, p<0.0000),-1.1265(t=-5.4328, p<0.0000)$, and -0.0297 $(t=-0.1822, p=0.8556)$, respectively, and those coefficients quantify the direct effects of three predictor variables on an outcome variable of le. 0.0002 $(t=15.2400, p<0.0000)$ is a regression coefficient relating GDP to le, which is adjusted for the effect of each predictor variable on GDP. 
Figure 4 shows the mediation effects in a path diagram. On an outcome variable of le, the indirect effects of GINI, income_h20, and poverty 1.90 are quantified by $a_{1} \cdot b_{1}, a_{2} \cdot b_{1}$ and $a_{3} \cdot b_{1}$, respectively, while the direct effects of those variables are quantified by $c_{1}^{\prime}, c_{2}^{\prime}$, and $c_{3}^{\prime}$, respectively. Based on the calculation, the indirect effects of GINI, income_h20, and poverty 1.90 on le are $1.0909,-1.2908$, and -0.8951 , respectively. According to the sequential steps for mediation analysis, it shows that on the relationship with le, povertyl.90 is fully mediated by $G D P$, whereas GINI and income $h 20$ are partially mediated by GDP. A test of whether there is full mediation or partial mediation depends on whether the coefficient of $c_{i}^{\prime}$ is statistically significant on the premise that the coefficient $\left(b_{i}\right)$ of the mediator variables is statistically significant. It is a test of whether the relationship between a predictor variable and an outcome variable is fully accounted for by a mediator variable (Baron \& Kenny, 1986; MacKinnon et al., 2007b). In Figure 4, the effect $\left(b_{1}\right)$ of GDP on life expectancy denotes statistical significance. The coefficient $c_{3}^{\prime}$ shows no significance. It denotes that the relationship between poverty headcount ratio at $\$ 1.90$ a day and life expectancy is fully mediated by GDP. But the coefficients $c_{1}^{\prime}$ and $c^{\prime}{ }_{2}$ are statistically significant, and then the absolute values of $c^{\prime}{ }_{1}$ and $c_{2}^{\prime}$ are less than the absolute values of $c_{1}$ and $c_{2}$. It signifies that the effect of each of Gini index and income share held by highest $20 \%$ on life expectancy is partially mediated by GDP.

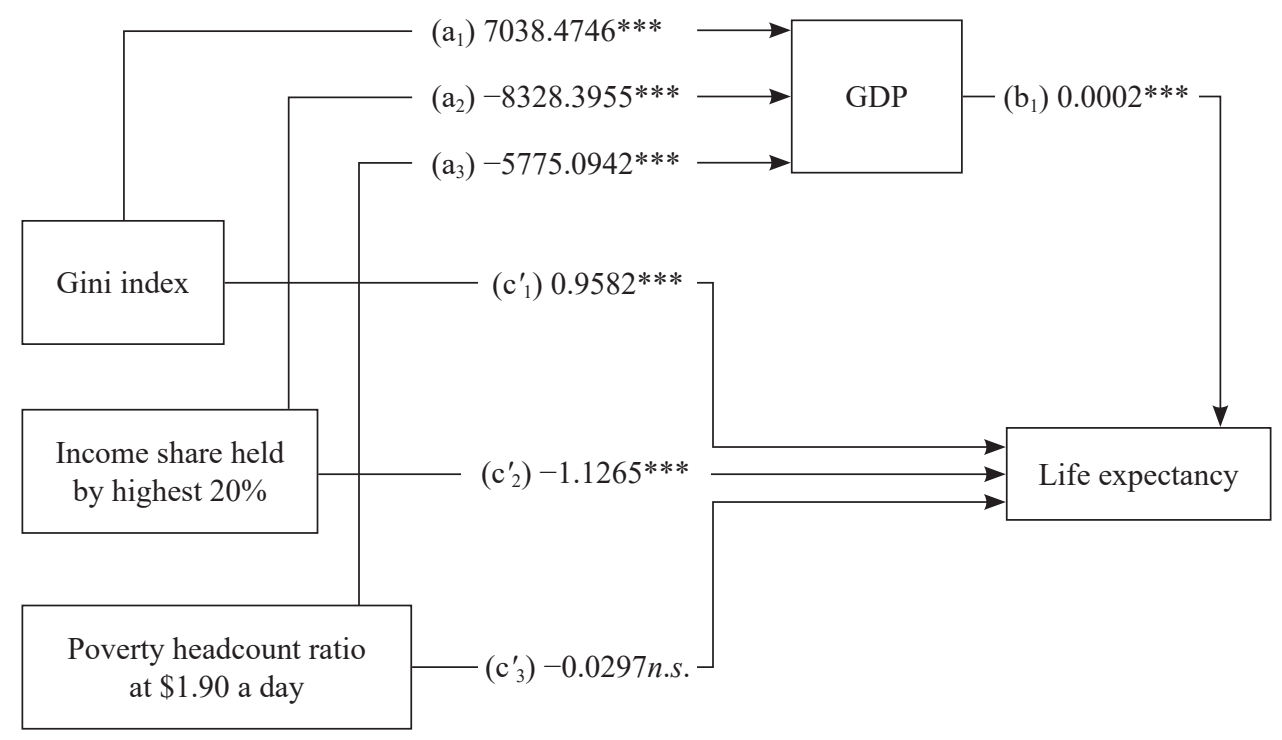

Figure 4. The direct and indirect effects of three variables specified for income inequality on life expectancy

Note: * indicates significance at the $10 \%$ level, $* *$ at the $5 \%$ level, and $* * *$ at the $1 \%$ level, respectively; $n$.s. corresponds to not significant 
Judging from the findings, it is clear that GDP mediates the relationship between life expectancy and three variables characterising income inequality. And with respect to each of three relationships mediated by GDP, the proportions mediated can be computed (MacKinnon et al., 2007b). The equation is as follows:

$$
1-\left(c^{\prime} / c\right)
$$

When it comes to the relationship between life expectancy and each variable, the proportions mediated by GDP are as follows: Gini index is 53\% (0.5324); income share held by highest $20 \%$ is $53 \%(0.5340)$; and poverty headcount ratio at $\$ 1.90$ a day is $97 \%(0.9678)$, respectively.

\section{DISCUSSION AND CONCLUSION}

First, to examine mediation of GDP on the relationship between life expectancy and income inequality, this study set up mediation model with GDP as a mediator variable, life expectancy as an outcome variable, and three variables specified for income inequality as predictor variables. The findings rested on the significance level of each coefficient have shown that while the relationship between life expectancy and poverty headcount ratio at $\$ 1.90$ a day is fully mediated by GDP, the relationship between life expectancy and each of Gini index and income share held by highest $20 \%$ is partially mediated by GDP. In mediation analysis conducted in two parts: the direct effect and the indirect effect, the findings have shown that concerning the effect of each variable on life expectancy, the effect size became less in comparison with when it is examined with no consideration of a mediator variable of GDP. Although there is no change about the sign of each coefficient which describes the nature of a relationship between two variables, it has been substantiated that GDP has a significant role as a mediator in each relationship, given the change in the effect size of each coefficient between before and after addition of GDP. In order to more effectively understand the effect of mediation, the proportions mediated were computed (Ditlevsen et al., 2005; Mackinnon \& Dwyer, 1993; Sobel, 1982). When it comes to the relationship between life expectancy and each variable characterising income inequality, the proportions mediated by GDP are as follows: Gini index is $53 \%(0.5324)$, income share held by highest $20 \%$ is $53 \%(0.5340)$, and poverty headcount ratio at $\$ 1.90$ a day is $97 \%(0.9678)$. Each numerical value shown in percentage terms supports the findings inferred from the significance level. It shows that GDP mediates the relationship between life expectancy and three variables characterising income inequality. And by extension, it can be interpreted that the relationship between life expectancy and income inequality is mediated by GDP (Dollard \& Neser, 2013). 
Given that the study exhibits a new approach to the study of the relationship between life expectancy and income inequality by setting up GDP as a mediator, it certainly deserves our full attention (Agénor, 2016; Cingano, 2014; Deaton, 2003; Egawa, 2013). This study proved that there is significant correlation between income inequality and GDP and life expectancy and that GDP acts mediating role between income inequality and life expectancy (Kim \& Kim, 2014, 2015, 2017, 2018). The structural and compositional method offers an in-depth view of the relationship. Given the glaring lack of a discerning examination regarding a mediating role of GDP, this study can be seen as the first in a stream of research investigating the effects of income inequality on life expectancy.

\section{ACKNOWLEDGEMENTS}

The author would like to thank Min-Sun Kim for assisting in collecting and sorting out the sample in this article.

\section{REFERENCES}

Acemoglu, D., \& Johnson, S. (2007). Disease and development: The effect of life expectancy on economic growth. Journal of Political Economy, 115(6), 925-985. https://doi.org/10.1086/529000

Acemoglu, D., \& Robinson, J. A. (2002). The political economy of the Kuznets curve. Review of Development Economics, 6(2), 183-203. https://doi.org/10.1111/1467 $-9361.00149$

Agénor, P. R. (2016). Caught in the middle? The economics of middle-income traps. Journal of Economic Surveys, 31(3), 771-791. https://doi.org/10.1111/joes .12175

Atkinson, A. B. (1970). On the measurement of inequality. Journal of Economic Theory, 2(3), 244-263. https://doi.org/10.1016/0022-0531(70)90039-6

Banister, J., \& Zhang, X. (2005). China, economic development and mortality decline. World Development, 33(1), 21-41. https://doi.org/10.1016/j.worlddev.2004.09 .003

Baron, R. M., \& Kenny, D. A. (1986). The moderator-mediator variable distinction in social psychological research: Conceptual, strategic, and statistical considerations. Journal of Personality and Social Psychology, 51(6), 1173-1182. https://doi.org/10.1037/0022-3514.51.6.1173

Barro, R. J. (2000). Inequality and growth in a panel of countries. Journal of Economic Growth, 5(1), 5-32. https://doi.org/10.1023/a:1009850119329

Bloom, D. E., \& Canning, D. (2007). Commentary: The Preston curve 30 years on Still sparking fires. International Journal of Epidemiology, 36(3), 498-499. https://doi.org/10.1093/ije/dym079 
Ceriani, L., \& Verme, P. (2011). The origins of the Gini index: Extracts from Variabilità e Mutabilità (1912) by Corrado Gini. The Journal of Economic Inequality, 10(3), 421-443. https://doi.org/10.1007/s10888-011-9188-x

Chong, A. (2004). Inequality, democracy, and persistence: Is there a political Kuznets curve? Economics and Politics, 16(2), 189-212. https://doi.org/10.1111/j.1468 $-0343.2004 .00137 . \mathrm{x}$

Cingano, F. (2014). Trends in income inequality and its impact on economic growth, OECD Social, Employment and Migration Working Papers, 163. Paris: OECD Publishing. https://doi.org/10.1787/5jxrjncwxv6j-en

Coburn, D. (2000). Income inequality, social cohesion and the health status of populations: The role of neo-liberalism. Social Science \& Medicine, 51(1), 135-146. https://doi.org/10.1016/s0277-9536(99)00445-1

Dalgaard, C.-J., \& Strulik, H. (2014). Optimal aging and death: Understanding the Preston curve. Journal of the European Economic Association, 12(3), 672-701. https://doi.org/10.1111/jeea.12071

De Vogli, R., Mistry, R., Gnesotto, R., \& Cornia, G. A. (2005). Has the relation between income inequality and life expectancy disappeared? Evidence from Italy and top industrialised countries. Journal of Epidemiology \& Community Health, 59(2), 158-162. https://doi.org/10.1136/jech.2004.020651

Deaton, A. (2003). Health, inequality, and economic development. Journal of Economic Literature, 41(1), 113-158. https://doi.org/10.1257/002205103321544710

Deininger, K., \& Squire, L. (1996). A new data set measuring income inequality. The World Bank Economic Review, 10(3), 565-591. https://doi.org/10.1093/ wber/10.3.565

Ditlevsen, S., Christensen, U., Lynch, J., Damsgaard, M. T., \& Keiding, N. (2005). The mediation proportion: A structural equation approach for estimating the proportion of exposure effect on outcome explained by an intermediate variable. Epidemiology, 16(1), 114-120. https://doi.org/10.1097/01.ede.0000147107 .76079 .07

Dollard, M. F., \& Neser, D. Y. (2013). Worker health is good for the economy: Union density and psychosocial safety climate as determinants of country differences in worker health and productivity in 31 European countries. Social Science \& Medicine, 92, 114-123. https://doi.org/10.1016/j.socscimed.2013.04.028

Egawa, A. (2013). Will income inequality cause a middle-income trap in Asia? Bruegel, 797. https://core.ac.uk/download/pdf/17733163.pdf

Fitrianto, A., \& Midi, H. (2013). Standardized simple mediation model: A numerical example. World Applied Sciences Journal, 22(8), 1135-1139. https://doi.org/ 10.5829/idosi.wasj.2013.22.08.681

Freedman, L. S., Graubard, B. I., \& Schatzkin, A. (1992). Statistical validation of intermediate endpoints for chronic diseases. Statistics in Medicine, 11(2), 167178. https://doi.org/10.1002/sim.4780110204

Hagen, E. E. (1963). How economic growth begins: A theory of social change. Journal of Social Issues, 19(1), 20-34. https://doi.org/10.1111/j.1540-4560.1963 .tb00428.x 
Kawachi, I., \& Kennedy, B. P. (1999). Income inequality and health: Pathways and mechanisms. Health Services Research, 34(1 Pt 2), 215-227. Retrieved from https://www.ncbi.nlm.nih.gov/pmc/articles/PMC1088996/pdf/hsresearch00017 -0022.pdf

Kennedy, B. P., Kawachi, I., \& Prothrow-Stith, D. (1996). Income distribution and mortality: Cross sectional ecological study of the Robin Hood index in the United States. BMJ (Clinical Research Ed.), 312(7037), 1004-1007. Retrieved from https://www.ncbi.nlm.nih.gov/pmc/articles/PMC2350807/pdf/bmj00538-0022 .pdf

Kim, J. I., \& Kim, G. (2014). Factors affecting the survival probability of becoming a centenarian for those aged 70 , based on the human mortality database: Income, health expenditure, telephone, and sanitation. BMC Geriatrics, 14(1), 113. https://doi.org/10.1186/1471-2318-14-113

Kim, J. I., \& Kim, G. (2015). Country-level socioeconomic indicators associated with healthy life expectancy: Income, urbanization, schooling, and internet users: 2000-2012. Social Indicators Research, 129(1), 391-402. https://doi.org/10 .1007/s11205-015-1107-2

Kim, J. I., \& Kim, G. (2017). Socio-ecological perspective of older age life expectancy: income, gender inequality, and financial crisis in Europe. Globalization and Health, 13(1). https://doi.org/10.1186/s12992-017-0279-8

Kim, J. I., \& Kim, G. (2018). Effects on inequality in life expectancy from a social ecology perspective. BMC Public Health, 18(1). https://doi.org/10.1186/s12889-0185134-1

Kuznets, S. (1955). Economic growth and income inequality. The American Economic Review, 45(1), 1-28. Retrieved from http://www.jstor.org/stable/1811581

List, J. A., \& Gallet, C. A. (1999). The Kuznets curve: What happens after the inverted-U? Review of Development Economics, 3(2), 200-206. https://doi.org/10.1111/1467 $-9361.00061$

Lutz, W., \& Kebede, E. (2018). Education and health: Redrawing the Preston curve. Population and Development Review, 44(2), 343-361. https://doi.org/10.1111/ padr.12141

Lynch, J. W., Kaplan, G. A., Pamuk, E. R., Cohen, R. D., Heck, K. E., Balfour, J. L., \& Yen, I. H. (1998). Income inequality and mortality in metropolitan areas of the United States. American Journal of Public Health, 88(7), 1074-1080. https://doi.org/10.2105/ajph.88.7.1074

Lynch, J. W., Smith, G. D., Kaplan, G. A., \& House, J. S. (2000). Income inequality and mortality: Importance to health of individual income, psychosocial environment, or material conditions. BMJ, 320(7243), 1200-1204. https://doi.org/10.1136/ bmj.320.7243.1200

Lynch, J., Smith, G. D., Hillemeier, M., Shaw, M., Raghunathan, T., \& Kaplan, G. (2001). Income inequality, the psychosocial environment, and health: Comparisons of wealthy nations. The Lancet, 358(9277), 194-200. https://doi.org/10.1016/s01406736(01)05407-1 
Mackinnon, D. P., \& Dwyer, J. H. (1993). Estimating Mediated Effects in Prevention Studies. Evaluation Review, 17(2), 144-158. https://doi.org/10.1177/0193841 x9301700202

MacKinnon, D. P., Fairchild, A. J., \& Fritz, M. S. (2007a). Mediation analysis. Annual Review of Psychology, 58, 593-614. https://doi.org/10.1146/annurev.psych .58 .110405 .085542

MacKinnon, D. P., Lockwood, C. M., Brown, C. H., Wang, W., \& Hoffman, J. M. (2007b). The intermediate endpoint effect in logistic and probit regression. Clinical Trials: Journal of the Society for Clinical Trials, 4(5), 499-513. https://doi.org/ 10.1177/1740774507083434

MacKinnon, D. P., Warsi, G., \& Dwyer, J. H. (1995). A simulation study of mediated effect measures. Multivariate Behavioral Research, 30(1), 41-62. https://doi .org/10.1207/s15327906mbr3001_3

Pickett, K. E., \& Wilkinson, R. G. (2015). Income inequality and health: A causal review. Social Science \& Medicine, 128, 316-326. https://doi.org/10.1016/j .socscimed.2014.12.031

Preston, S. H. (1975). The changing relation between mortality and level of economic development. Population Studies: A Journal of Demography, 29(2), 231-248. https://doi.org/10.1080/00324728.1975.10410201

Preston, S. H. (2007). The changing relation between mortality and level of economic development. International Journal of Epidemiology, 36(3), 484-490. https://doi.org/10.1093/ije/dym075

Rijnhart, J. J. M., Twisk, J. W. R., Chinapaw, M. J. M., de Boer, M. R., \& Heymans, M. W. (2017). Comparison of methods for the analysis of relatively simple mediation models. Contemporary Clinical Trials Communications, 7, 130-135. https://doi.org/10.1016/j.conctc.2017.06.005

Schnabel, S. K., \& Eilers, P. H. (2009). An analysis of life expectancy and economic production using expectile frontier zones. Demographic Research, 21, 109-134. Retrieved from https://www.jstor.org/stable/26349341

Sobel, M. E. (1982). Asymptotic confidence intervals for indirect effects in structural equation models. Sociological Methodology, 13, 290-312. https://doi.org/10 $.2307 / 270723$

Subramanian, S. V., \& Kawachi, I. (2004). Income inequality and health: What have we learned so far? Epidemiologic Reviews, 26(1), 78-91. https://oi/10.1093/epirev/ mxh003

Wilkinson, R. G. (1992). Income distribution and life expectancy. BMJ: British Medical Journal, 304(6820), 165-168. Retrieved from https://www.ncbi.nlm.nih.gov/ pmc/articles/PMC1881178/

Wilkinson, R. G. (2002). Unhealthy societies: The affliction of inequalities. London, UK: Routledge.

Wilkinson, R. G., \& Pickett, K. E. (2009). Income inequality and social dysfunction. Annual Review of Sociology, 35(1), 493-511. https://doi.org/10.1146/annurev -soc-070308-115926 